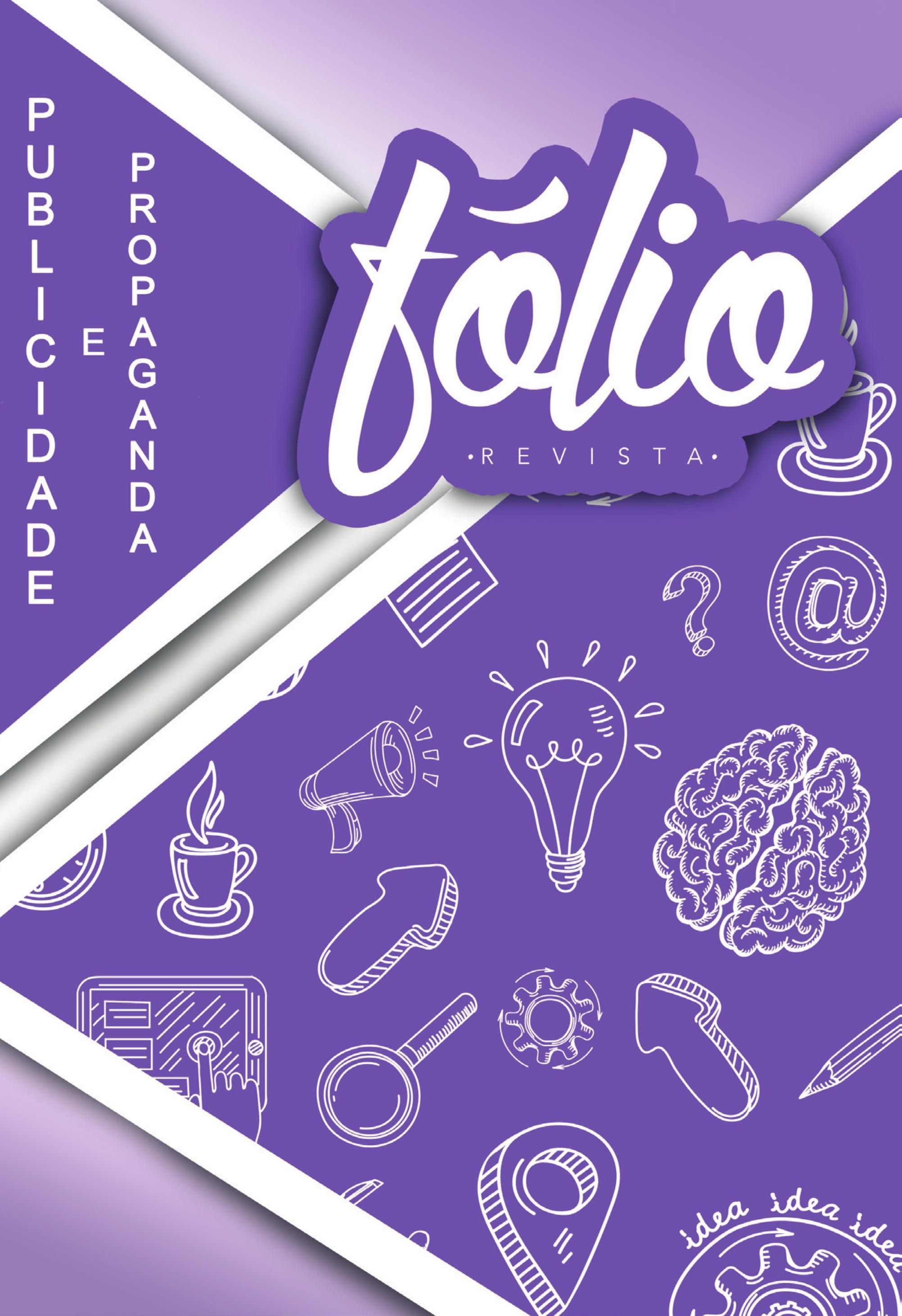




\title{
O visual merchandising e o vitrinismo: um estudo sobre a influência no comportamento do consumidor ${ }^{1}$
}

\section{Visual merchandising and vitrinism: a study about the influence on consumer behavior} Félix Diego Rehbein Fischer² Valéria Deluca Soares ${ }^{3}$

\begin{abstract}
Resumo
A presente pesquisa objetiva verificar a influência do visual merchandising e do vitrinismo no comportamento de compra do consumidor, no segmento do varejo de moda, em shopping centres da cidade de Porto Alegre. Para tal, os procedimentos metodológicos utilizados estão pautados na pesquisa exploratória, em uma abordagem qualitativa e quantitativa. Para a coleta de dados, definiu-se pela pesquisa bibliográfica e pela aplicação de um questionário, em uma amostragem não probabilística por conveniência, composta por indivíduos de ambos os sexos, entre 18 e 55 anos, que realizam compras no segmento varejista de moda, em shoppings centers localizados na cidade de Porto Alegre. A partir da técnica de Análise de Conteúdo, verificou-se que as decisões de compra são influenciadas pela correta elaboração de uma vitrine e pela aplicação das técnicas de visual merchandising no estabelecimento comercial. Viu-se que a vitrine é uma ferramenta de atração de clientes para uma loja, além de um diferencial competitivo. Pode-se inferir que a forma como os produtos são alocados no interior da mesma induz à compra, despertando no consumidor uma sensação de necessidade ou vantagem, que faz com que ele adquira itens que não tinha a intenção de comprar.
\end{abstract}

Palavras-chave: Vitrinismo. Visual merchandising. Varejo de moda. Comportamento do consumidor. Shopping Centers de Porto Alegre.

\section{Abstract}

The present research aims to verify the influence of visual merchandising and window dressing on consumer buying behavior in the fashion retail segment in shopping centers in the city of Porto Alegre. For this, the methodological procedures used are based on the exploratory research, in a qualitative and a quantitative approach. The data collection was defined by a bibliographic research and the application of a questionnaire, in a non-probabilistic sample for convenience, composed of individuals of both male and female sexes, between 18 and 55 years old who purchase in the retail segment of fashion in malls located in the city of Porto Alegre. From the Content Analysis technique, it was verified that the purchase decisions are influenced by the correct elaboration of a shop window and by the application of visual merchandising techniques in the commercial establishment. It has been seen that a shop window is a tool to attract customers to a store, in addition to a competitive differential. It can be inferred that the way products are allocated inside induces the purchase, awakening in the consumer a sense of need or advantage that causes him to purchase items he did not intend to buy. Keywords: Visual merchandising. Fashion retail. Consumer behavior. Porto Alegre Shopping Centers.

\footnotetext{
1 Artigo resultante da monografia realizada, por Félix Diego Rehbein Fischer, para obtenção do título de Bacharel em Publicidade e Propaganda, junto ao Centro Universitário Metodista IPA, no segundo semestre de 2017.

2 Bacharel em Publicidade e Propaganda pelo Centro Universitário Metodista do Sul IPA. Atua na área de gestão em empresa do seguimento varejista de moda, estando diretamente ligado à elaboração e aplicação de estratégias de visual merchandising da empresa. Contato: felix_fdrf@hotmail.com

3 Doutora em Comunicação Social. Jornalista. Professora do Centro Universitária Metodista IPA. Contato: valeriadeluca@hotmail.com
} 


\section{Introdução}

I m virtude do atual cenário de ampla concorrência e bombardeamento de informações, que atinge os consumidores através dos mais diversos meios de comunicação, uma das táticas utilizadas pelo mercado varejista passou a ser o merchandising. $O$ presente artigo tem como tema central a utilização das técnicas de visual merchandising e de vitrinismo como ferramentas que influenciam o comportamento do consumidor.

O merchandising e o vitrinismo são técnicas oriundas do marketing de ponto de venda, enquadrando-se como ferramentas de promoção. São utilizadas, principalmente, nos setores de vestuário e supermercadista. A explosão deste uso ocorreu no início da década de 1950, quando o setor importou tais técnicas dos mercados norte-americano e europeu.

O visual merchandising consiste, de forma geral, na utilização das diversas técnicas que o compõem a ordenação do espaço interno de uma loja, com o intuito influenciar o comportamento de compra do consumidor. Pode-se, através dela, induzir o consumidor a adquirir produtos específicos ou complementares.

O vitrinismo, por sua vez, é um dos braços do merchandising de maior relevância para o segmento de varejo, tendo como função principal atrair a atenção do consumidor. Para isso, utiliza-se técnicas de comunicação não verbal e design para atrair o cliente ao interior do ambiente comercial e persuadi-lo ao consumo de determinados produtos. Tem, portanto, a necessidade de ser convidativa e estar alinhada ao comportamento e às necessidades do público alvo do varejista.

Utilizar-se-á, como delimitação para esta pesquisa, o segmento de varejo de moda localizados nos shoppings centers da cidade de Porto Alegre, sendo eles o cenário do estudo. A finalidade da pesquisa está centrada em compreender a efetividade da utilização das técnicas de visual merchandising e vitrinismo como ferramentas de interferência sobre o comportamento de compra do consumidor.

O setor varejista é responsável por 12,3\% do Produto Interno Bruto Brasileiro (PIB), sendo assim, possui intensa influência sobre os indicadores econômicos do país, conforme aponta pesquisa elaborada pelo Departamento de Pesquisas e Estudos Econômicos do Banco Bradesco (DEPEC) 4 . No entanto, este é o primeiro setor a sofrer com a atual crise econômica, o que torna ainda mais importante a correta utilização de qualquer técnica que possa servir para impulsionar as vendas.

Segundo artigo de Heloisa Menezes, diretora técnica do Serviço Brasileiro de Apoio às Micro e Pequenas Empresas (SEBRAE) ${ }^{5}$, publicado na revista Conhecer, editada pelo mesmo, em todo o país, há cerca de 780 mil lojas de vestuário, calçados e acessórios, além de 318 mil microempreendedores individuais, 383 mil microempresas e 79 mil empresas de pequeno porte. Tais números abrem um vasto campo para a aplicação dos resultados obtidos através da elaboração desta proposta de pesquisa, que possui a finalidade de corroborar com a efetividade da aplicação das referidas técnicas.

Diante do cenário atual, onde as empresas do segmento varejista buscam novas técnicas para conquistar a atenção do cliente, o visual merchandising e o vitrinismo vêm ganhando espaço na gestão de marketing das empresas do segmento de varejo de moda. Assim, o presente estudo tem como finalidade responder à pergunta: qual a influência do visual merchandising e do vitrinismo no comportamento de compra do consumidor, no segmento de varejo de moda, em shoppings centers de Porto Alegre?

Levando-se em consideração a crescente concorrência entre as empresas do segmento varejista de moda, tem-se como hipótese que a correta utilização das técnicas de visual merchandising, em especial do vitrinismo, exercem expressiva influência no comportamento de compra do consumidor. Acredita-se que são capazes de despertar a intenção de compra de um indivíduo, através da correta utilização da vitrine, além de induzir o consumidor a adquirir determinados produtos, devi-

4 Disponível em <www.economiaemdia.com.br/EconomiaEmDia/ pdf/infset_comercio_varejista.pdf> Acesso em 17.04.2017, ás 11:00.

5 Disponível em <www.bibliotecas.sebrae.com.br/chronus/ ARQUIVOS_CHRONUS/bds/bds.nsf/c8874

f1b33de587fcc7641cb0f839ec2/\$File/5350.pdf> Acesso em 17.04.2017, ás 13:15. 
do à utilização de técnicas de visual merchandising para gerenciar a exposição dos produtos no ponto de venda.

Acredita-se que com base na interação gerada entre cliente e produto, através da correta elaboração de uma vitrine e colocação dos produtos no ponto de venda, a partir de uma estratégia de visual merchandising que leve em consideração o perfil do público-alvo da marca ou do estabelecimento comercial, é possível agir diretamente sobre o comportamento de compra do consumidor. Tal estratégia pode induzi-lo a adquirir produtos específicos, além de produtos adicionais, aumentando assim de forma significativa o faturamento da empresa.

Logo, o objetivo geral da pesquisa é verificar a influência do visual merchandising e do vitrinismo no comportamento de compra do consumidor, no segmento do varejo de moda, em shopping centers da cidade de Porto Alegre. São os objetivos específicos: compreender o visual merchandising no composto de marketing; descrever o uso do vitrinismo no segmento de varejo de moda; caracterizar o comportamento do consumidor que frequenta os shopping centers da cidade de Porto Alegre, com ênfase no segmento varejista de moda, no que tange ao visual merchandising e ao vitrinismo.

Posto isto, cabe informar que o tema foi escolhido pelo pesquisador devido o interesse na área de marketing e no desenvolvimento de campanhas promocionais e de venda. O pesquisador atua na área de visual merchandising e vitrinismo há oito anos. Realizou trabalhos no segmento farmacêutico e varejista de moda, a qual se dedica atualmente. Sendo assim, os resultados obtidos através deste estudo podem contribuir no seu desenvolvimento profissional. As respostas encontradas para a questão da pesquisa podem servir, também, para a elaboração de um plano de negócio, que visa a criação de uma empresa de desenvolvimento de ações de visual merchandising e vitrinismo pensadas de forma individual para cada cliente.

A temática abordada ganha peso visto que, cada vez mais, as empresas do segmento varejista de moda têm mostrado interesse na pesquisa e no desenvolvimento de novos modos de pro- moção de imagem, visando atingir um número maior de consumidores. Outro fator relevante é o fato das mesmas demonstrarem uma crescente preocupação em tornar as lojas mais atrativas ao cliente, o que tem influência direta das técnicas de visual merchandising. Também é relevante destacar que uma vez que se constitua uma linguagem não-verbal assertiva, através da correta concepção de uma vitrine e do ambiente interno de uma loja, torna-se possível influenciar o comportamento de compra do cliente, gerando assim uma maior lucratividade ao negócio.

Acredita-se que os resultados obtidos com base nesta pesquisa podem orientar mudanças na carteira de investimentos do setor de marketing de uma empresa, bem como sugerir modificações no âmbito das campanhas internas e de promoção das mesmas. Pode, ainda, propor modificações ou maior foco na utilização das técnicas de visual merchandising e vitrinismo por parte das empresas, com o intuito de melhorar os resultados financeiros da mesma.

Os dados obtidos através desta proposta de pesquisa podem, ainda, ser a base para os profissionais da área de visual merchandising e vitrinismo, na concepção de suas vitrines e elaboração dos conceitos que definirão a disposição dos produtos no ponto de venda. Permitem, além disso, compreender como as referidas técnicas, de fato, influenciam o comportamento de compra do consumidor.

Esta proposta se caracteriza como uma pesquisa exploratória, em um estudo de recepção, que visa identificar o grau de interferência das técnicas de merchandising e vitrinismo sobre o comportamento de compra do consumidor, segundo Gil (2000; 2008), Piovesan e Temporini (1995). A pesquisa exploratória possui um caráter mais flexível, uma vez que tal flexibilidade permite uma análise mais aprofundada de como as ferramentas de visual merchandising e vitrinismo interferem no comportamento de compra do consumidor no segmento varejista de moda.

Em complemento ao exposto, se utiliza da abordagem qualitativa, conforme esclarecem Fonseca (2002), Minayo (2001) e Casarin (2011). Tal perspectiva explora uma metodologia predominantemente descritiva, onde a maior preocupação passa 
a ser explicar como ocorre determinado fenômeno e como ele interfere nas relações humanas.

A partir do exposto, o presente estudo conta com três formas de coleta de dados: a pesquisa bibliográfica, a pesquisa documental e aplicação de um questionário com questões mistas, seguindo os apontamentos de Gil (2008), Chagas (2000), Motta, Matar e Oliveira (2014), Chagas (2000). Optou-se por uma amostragem não probabilística por conveniência, conforme os conceitos de Mat$\operatorname{tar}$ (1996) e Ochoa (2015). A amostra foi composta por pessoas de ambos os gêneros, a partir de 18 anos e sem limite de idade, que tenham realizado compras no varejo de moda e possuam acesso a rede social Facebook, uma vez que o questionário foi veiculado exclusivamente através do mesmo, não havendo assim qualquer limitação demográfica para a amostra.

Coletados os dados, as respostas referentes às questões fechadas foram apresentadas, analisadas e interpretadas, por meio da técnica Análise de Conteúdo (BARDIN, 1977). Todas as informações são estudadas à luz do conteúdo apresentado, a partir da pesquisa bibliográfica e documental.

\section{O setor varejista}

Para o desenvolvimento do estudo, são apresentados dados relevantes para a pesquisa, como números do setor varejista de moda, indústria têxtil e dados referentes ao segmento de shoppings centers. Também são apresentados dados básicos a respeito da cidade de Porto Alegre, local onde se dá a pesquisa.

Conforme informações publicadas na edição virtual da Revista Exame 6 , o segmento de varejo gera um em cada quatro empregos do setor privado no Brasil. Sendo assim, é um setor relevante para a economia do país e um dos responsáveis por mantê-la aquecida. Pesquisa elaborada pelo Departamento de Pesquisas e Estudos Eco-

6 Disponível em <http://exame.abril.com.br/revista-voce-sa/ edicoes/193/noticias/onde-o-varejo-cresce> Acesso em 11.04.2017, ás 19:00. nômicos do Banco Bradesco (DEPEC)7, o setor é responsável por $12 \%$ do PIB brasileiro e $43 \%$ do comércio geral. Também segundo o DEPEC, há momentos do ano em que o varejo sofre aquecimentos momentâneos, sendo estes as principais datas comemorativas do ano, como Natal, dia das mães, dia dos namorados, dia dos pais, dia das crianças, além da recém-chegada ao Brasil, a Black Friday.

Quanto à indústria têxtil, a Associação Brasileira da Indústria Têxtil e de Confecção (Abit), aponta que a produção atingiu 6,7 bilhões de peças (vestuário+meias e acessórios+cama, mesa e banho). Ressalta ainda que o Brasil ainda é a única cadeia de produção completa do ocidente, ou seja, possui desde a produção da fibra até o varejo, além de estar presente nas cinco maiores semanas de moda do mundo 8 .

Conforme dados da Euromonitor', divulgados pelo portal eletrônico da companhia Restoque SA, especificamente o segmento varejista de moda corresponde a $2,5 \%$ do PIB de serviços do Brasil, no ano de 2015, alcançando um montante de $\mathrm{R} \$ 93$ bilhões. A pesquisa aponta ainda que, entre 2010 e 2015, o setor de vestuário no Brasil apresentou um crescimento de 6,3\% ao ano. Também segundo dados da Restoque SA, a principal localização de lojas no Brasil são os shopping centers que, no período entre 2006 e 2015, tiveram um aumento de $53 \%$ no número de estabelecimentos, passando de 351 para 538 unidades. Devido a esta intensa expansão, o faturamento cresceu 203\% no mesmo período, passando de $\mathrm{R} \$ 50$ bilhões para $\mathrm{R} \$ 152$ bilhões.

Quanto à cidade Porto Alegre, onde se dá este estudo, segundo o Instituto Brasileiro de Geografia e Estatística (IBGE)10, tem uma população estimada em 1.484.941 de habitantes no ano de

7 Disponível em <www.economiaemdia.com.br/EconomiaEmDia/ pdf/infset_comercio_varejista.pdf> Acesso em 12.04.2017, as 23:00.

8 Disponível em < http://www.abit.org.br/cont/perfil-do-setor> Acesso em 23.04.2017, as 16:10.

9 Disponível em < http://www.restoque.com.br/conteudo_pt.asp?i dioma $=0 \&$ conta $=28 \&$ tipo $=41515>$ Acesso em 23.04.2017, as 15:00.

10 Disponível em <http://cidades.ibge.gov.br/xtras/temas.php?lan $g=\& \operatorname{codmun}=431490 \&$ idtema $=16 \&$ search $=$ rio-grande-do-sul|portoalegre|sintese-das-informacoes > Acesso em 05/09/2017, as 14:00. 
2017, com rendimento per capta de $\mathrm{R} \$ 1.000,00$ e uma média de rendimentos por domicílio de $\mathrm{R} \$ 4879,96$. Segundo o site da Prefeitura Municipal de Porto Alegre, a cidade está dividida em 81 bairros ${ }^{11}$.

Segundo a Associação Brasileira de Shopping Centers (ABRASCE), Porto Alegre conta com 15 shopping centers, com uma área bruta locável de $433.107 \mathrm{~m}^{2}$. Ainda segundo a ABRASSE, no ano de 2016, eram 558 shoppings no Brasil com um faturamento de 157,9 bilhões de reais, gerando 1.016.428 empregos e um tráfego de pessoas intenso, estimando 439 milhões de visitas ao mês. ${ }^{12}$

\section{Visual merchandising, vitrinismo e o comportamento do consumidor}

Para a realização da pesquisa, como informado, foi disponibilizado, através do Facebook, um questionário, entre os dias 01 e 21 de setembro de 2017. Foram obtidas 44 respostas neste período. Do total de respondentes $79,5 \%$ são do gênero feminino e 20,5\% do masculino. Quanto à faixa etária, $47,7 \%$ da amostra tem entre 26 e 35 anos, $27,3 \%$ entre 18 e 25 anos, 18,2\% entre 36 e 45 anos e os $6,8 \%$ restantes entre 46 e 55 anos. A renda de $65,9 \%$ da amostra é de até 3 salários mínimos, $25 \%$ possuem renda entre 4 e 6 salários mínimos, indivíduos com renda entre 7 e 9 salários mínimos ou acima de 10 são 4,5\% da amostra em cada faixa.

Usa-se, a partir de agora, a Análise de Conteúdo (BARDIN,1977), como indicado, para a realização da apresentação, análise e interpretação dos dados. Assim, tem-se como categorias de análise: a expansão dos shoppings centers como local de interação social; a vitrine como ferramenta para atração de clientes; e o layout de loja e o visual merchandising como indutor de compras por impulso. Destaca-se anda, que se optou por apresentar, em itálico no texto, manifestações nas

11 Disponivel em <http://www2.portoalegre.rs.gov.br/spm/default. php?p_secao=129> Acesso em 05/09/2017, as 14:30.

12 Disponível em <http://www.abrasce.com.br/monitoramento/ evolucao-do-setor> Acesso em 05/09/2017, as 15:00. perguntas abertas, deixadas pelos respondentes do questionário. Entende-se que é uma forma de dar mais ênfase à análise.

Posto isto, segue-se com os resultados alcançados.

\section{Categoria 1: A expansão dos shoppings centers como local de interação social}

Com base na análise das respostas obtidas, nota-se que $61,4 \%$ da amostra opta por realizar compras no seguimento varejista de moda em shoppings centers, ao invés do comércio de rua. Tal hábito explica a forte expansão do setor que vem ocorrendo no Brasil nos últimos anos. Conforme aponta a Associação Brasileira de Shopping Centers (ABRASCE) no ano de 2016, eram 558 shoppings no Brasil com um faturamento de 157,9 bilhões de reais, gerando 1.016 .428 empregos e um tráfego de pessoas intenso, estimando 439 milhões de visitas ao mês.

Rech (2002) salienta que o consumo de moda está diretamente ligado às mudanças sociais e antropológicas. Estas, por sua vez, estão diretamente ligadas à preferência da população por realizar suas compras neste tipo de estabelecimento. Ao optarem por shoppings, a amostra leva em consideração questões referentes à segurança e aumento da violência, à comodidade de ter diversas lojas reunidas em um único local e o conforto de estar em um ambiente climatizado e alheio a quaisquer fatores climáticos.

Para Lipovetsky (2009) e Barnard (2003), a moda é uma importante ferramenta de interação social e comunicação não-verbal. Percebe-se assim que alguns shoppings se tornaram local de encontro de segmentos específicos da sociedade, sendo inclusive, em alguns casos, restritivos. Algumas pessoas não frequentam um shopping em específico por ele ser considerado de elite ou ao contrário, popular demais. Tais ambientes, assim como a moda, tornaram-se um meio de afirmação pessoal e de estabelecimento de grupos de interação social.

Tais questões estão diretamente ligadas aos fatores psicossociais internos e externos, aponta- 
dos por Kotler (1998), como determinantes para as decisões do consumidor. Ao observar que $75 \%$ da amostra realizam suas compras em shoppings centers da cidade de Porto Alegre em detrimento das lojas de rua, é possível inferir que fatores sociais e culturais, como violência e classe social, são de extrema relevância.

Aos fatores anteriormente citados, juntam-se aspectos pessoais, como a necessidade de agilidade e de comodidade; e psicológicos, como a percepção do shopping como a melhor opção para realizar suas compras. Isto reforça a sensação de que lojas situadas em shoppings centers são a melhor opção para realizar compras no segmento varejista de moda.

\section{Categoria 2: A vitrine como ferramenta para atração de clientes}

Segundo o site do Serviço Brasileiro de Apoio às Micro e Pequenas Empresas (SEBRAE), a vitrine é a principal ferramenta de interface entre o consumidor e a loja. A correta elaboração desperta a atenção do público alvo do estabelecimento. Bigal (2000) ressalta que a vitrine foi a primeira forma de mídia desenvolvida pelo varejo com o intuito de atrair clientes. Tais afirmações ganham peso à medida que 95,5\% da amostra considera a vitrine um diferencial competitivo. Em análise mais detaIhada, os respondentes destacaram que a vitrine é o cartão de visitas da loja.

Demetresco e Maier (2004) ressaltam que a superfície de vidro da vitrine tem como função aumentar do desejo de posse do cliente pelo produto exposto, uma vez que impede o contato do mesmo com ele. Tal fato é reiterado ao perceber que parte dos respondentes informaram que a vitrine dispara o desejo de posse de um produto, despertando assim a intenção de compra, ponto ressaltado por Gusmão (2009). Ele considera que a vitrine é o vendedor silencioso da loja, sendo responsável por $50 \%$ das vendas de um estabelecimento comercial. Ainda segundo autor, a vitrine não é somente o cartão de visitas da loja, mas também o convite a compra mais efetiva que a mesma pode entregar para seu cliente. Esta colocação pode ser verificada, em respostas ao ques- tionário aplicado, como: "A vitrine é o convite para que o cliente possa entrar na loja. E, todo cliente gosta de um bom convite".

Ao observar respostas obtidas na pesquisa, como: "A vitrine diz muito sobre a loja. É uma maneira de mostrar e se diferenciar de outras lojas" ou "A vitrine é o impulso para entrar na loja ou não", é possível corroborar os apontamentos realizados pelos autores citados anteriormente. Complementarmente, Cobra (2007) aponta a vitrine como uma complexa ferramenta de comunicação não-verbal e a divide em diversas categorias, com funções de comunicação distintas. Ressalta ainda que a correta escolha do modelo de vitrine garante o sucesso da mesma. Observa que a vitrine deve interagir com o público alvo, estando alinhada ao conceito da marca e à cultura, instigando a curiosidade através de um delicado convite ao interior da loja. Logo, cria uma atmosfera única sendo capaz de envolver o cliente na história que conta. Os pontos levantados anteriormente são complementados ao observar respostas ao questionário, como: "É na vitrine que se vê a proposta da loja, o estilo e tudo mais".

Tais fatores dão peso as observações de Cobra (2007), quando destaca a necessidade da concepção de um modelo de vitrine específico para cada momento, ou seja, é necessário criar vitrines que respeitem pontos relacionados às sazonalidades, aos períodos específicos do ano e às datas comemorativas, além dos lançamentos de coleção e liquidações. $O$ intuito é gerar uma comunicação mais fluida com o cliente.

Gomes (2002), por sua vez, contribui destacando os princípios da Gestalt como indispensáveis para a elaboração de uma comunicação visual efetiva. Considera que a função de maior relevância para a vitrine é garantir que a mesma seja agradável aos olhos do público alvo. Tal elemento é de extrema importância, uma vez que 95,5\% dos respondentes afirmam ter entrado em uma loja devido à estética da vitrine. Isto é percebido em depoimento como: "A imagem tem o poder de atrair os olhares e aguçar a curiosidade". Conforme o autor, a correta aplicação de todos os princípios da Gestalt garante que a imagem formada é de fato agradável, sendo assim necessário observar tais princípios na elaboração de qual- 
quer forma de comunicação não verbal. Tal teoria ganha relevância quando os respondentes comentam sobre os aspectos que consideram mais importante em uma vitrine. Encontra-se respostas como: "Uma vitrine bem organizada" ou "um visual mais limpo, que de oportunidade de ver o que está sendo exposto".

$\mathrm{Na}$ coleta feita, os respondentes indicaram que entram na loja por acreditarem que a vitrine combina com seu estilo. Com base nas respostas coletadas, é possível observar que são diversos os fatores físicos que garantem o sucesso da vitrine, passando pelo layout, adequação ao ambiente em que a loja está inserida, a correta apresentação dos produtos, a unidade da vitrine, a escoIha correta dos produtos expostos, a precificação e até mesmo a forma de iluminação.

Nos dias atuais, a vitrine deixou de ser apenas um ponto para a exposição de produtos e passou a ser parte integrante da estratégia de marketing da empresa, lembra Bigal (2000). Assim, tem como função comunicar a identidade da marca, fazendo com que os consumidores se sintam representados pela vitrine. Paralelamente, Tavares e Irving (2009) apontam que através de diversos canais semióticos, as marcas deixaram de oferecer produtos e passaram a comercializar personalidades e estilo de vida. Tal afirmação corrobora com a pesquisa, uma vez que, quando questionados a respeito do motivo pelo qual a vitrine os levou ao interior da loja, os respondentes utilizaram respostas como: "Estampa e estilo das roupas", "O look combinava comigo" ou "os produtos combinavam com o meu estilo".

O fato uma fatia expressiva dos respondentes afirmarem que são atraídos pela vitrine devido ao fato de sentirem que combinam intimamente com o que está sendo exposto nela, a afirmação de Sackrider, Guidé e Hervé (2009) ganha peso. Eles apontam a vitrine como o ponto de partida para a ligação emocional entre o cliente e a marca.

Sobre as compras por impulso, 54,5\% dos respondentes da pesquisa informaram ter adquirido algum produto exposto em uma vitrine. Quando questionados a respeito do motivo pelo qual realizaram tal compra, também 54,5\% da amostra, apontam o fator beleza como o mais relevante no momento de uma compra por impulso. Isso que demonstra que mesmo para compras por impulso, o fator estético é o que possui maior peso.

Quanto ao fator de maior importância em uma vitrine, 54,5\% da amostra destaca que a beleza das mesmas possui maior relevância contra 45,5\% que apontam o preço como ponto principal. No entanto, ao analisar os comentários acerca de suas respostas é possível considerar que os respondentes ao apontar o preço como fator de maior peso, não se referiam ao valor dos produtos expostos e sim a apresentação do mesmo na vitrine. Tais questões são observadas em respostas como: "Os preços são muito importantes, pois se a loja não os coloca, eu nem entro, pois já penso que tudo será caro" e "O preço por lei tem que estar disponível para o cliente ver na vitrine sem ter que entrar na loja".

Com base nos pontos levantados até o presente momento, é possível observar que a concepção de uma vitrine assertiva deve levar em consideração o público que se quer atingir, a estética dos produtos, o conceito da marca, a clareza com que os produtos e preços são expostos. Todos estes pontos visam criar uma atmosfera atraente para o cliente.

\section{Categoria 3: O layout de loja e o visual merchandising como indutor de compras por impulso}

Conforme Blessa (2006), o visual merchandising se utiliza de técnicas como, designer, arquitetura, decoração, marketing olfativo e iluminação, com o intuito de induzir os clientes a comprar determinados produtos. Em resumo, a técnica trabalha o ponto de venda, visando torná-lo atrativo ao público alvo. Para Parente (2008), com base na correta aplicação de todas as técnicas de visual merchandising, cria-se uma atmosfera que cativa o cliente e o mantém na loja. $O$ termo atmosfera é utilizado, por Samara e Morsch (2009), para conceituar uma sensação que interfere diretamente sobre o comportamento de compra do consumidor. Sendo assim, tem interferência direta sobre o layout de um ponto de venda, uma vez que a disposição de produtos na vitrine, próximos ao caixa, 
entrada da loja ou em outros pontos em evidência para o cliente se utiliza deste conceito.

Bhalla e Anuraag (2009) salientam que o visual merchandising surge quando os comerciantes percebem que produtos que incialmente não eram considerados atrativos pelo consumidor poderiam passar a despertar o interesse do mesmo apenas pela relocação no ponto de venda. Tal fato soma-se aos dados obtidos pelo questionário em que $75 \%$ da amostra já comprou um produto além daquele que estava procurando apenas pelo fato do mesmo estar exposto juntamente ao item desejado. Este resultado corrobora com a afirmação de Blessa (2006) de que a visão possui um peso de 83\% no momento da decisão de compra.

Um fator apontado pelos respondentes como relevante para que esta situação ocorra é a disposição assertiva dos produtos, ou seja, os produtos expostos um ao lado do outro devem se complementar. Esta questão pode ser percebida em respostas como: "uma blusa exposta juntamente a um lenço que combine com ela" ou "a exposição de sapatos abaixo das araras de vestidos e até mesmo no interior dos provadores pode incentivar o cliente a prová-los juntamente com as peças escolhidas".

Bailey e Baker (2014) lembram que uma das funções do visual merchandising é garantir o correto aproveitamento dos espaços da loja, tornando-a agradável e convidativa ao público alvo. Esta afirmação foi mencionada pelos participantes da pesquisa, uma vez que $88,6 \%$ da amostra sugere que o layout da loja possui grande relevância para o consumidor. "Esse fator demonstra qual o segmento da loja, como também é a porta de entrada que fará o consumidor se interessar pela marca ou não", destacou um participante.

Além disso, tem como função garantir que o cliente encontre tudo o que busca de forma fácil e ágil e o induz, por diversas vezes, a comprar determinados produtos pelo simples fato de que combinam com aquilo que procurava ou viu na vitrine. "A ideia da combinação me atraiu", explica uma participante. "O contexto das peças dá muito certo, look completo. Às vezes, o consumidor não tem ideia para tendências e combinações de peças, então quando gosta de uma peça que está combinado com outra provavelmente vai le- var mais de uma peça", analisa outro participante. "Comprei o produto por combinar com o que eu tinha ido comprar", ressalta outro respondente.

Tais respostas dão sustentação ao apontamento de Blessa (2006). Ele destaca o fato de que os sentidos humanos possuem os seguintes pesos no momento da decisão de compra: $1 \%$ para paladar, 1,5\% para tato, 3,5\% para olfato, $11 \%$ para audição e 83\% para a visão. Sendo assim, infere-se que a correta alocação dos produtos no interior de uma loja causa estímulos visuais capazes de induzir o cliente a comprar determinados itens.

Outro dado obtido com a pesquisa mostra que $84,1 \%$ dos respondentes realizou a compra de itens expostos junto ao caixa de uma loja. Os participantes apontaram como fator decisivo, para tais compras, o valor do produto, a conveniência e o fato de que itens expostos desta forma tendem a despertar uma sensação de necessidade, mesmo quando esta não existe de fato. Itens apontados por eles como capazes de despertar essa intenção de compra são meias, cintos, carteiras, cuecas e itens de higiene e beleza. Este fato tem respaldo em Bauman (2001), ao colocar que o produto, na realidade, possui pouca importância, pois o que gera prazer de fato é o ato da compra, a simples sensação de posse de algo novo e que esteja na moda, ou que tenha sido adquirido previamente por indivíduos de seu círculo social.

\section{Inferências e ponderações}

Em um primeiro momento, identifica-se que os respondentes trouxeram informações que estão alinhadas aos dados obtidos com os levantamentos contidos no referencial teórico. Sendo assim, é possível observar qual a influência do visual merchandising e do vitrinismo no comportamento de compra do consumidor, no segmento de varejo de moda, em shoppings centers de Porto Alegre.

A hipótese levantada como resposta ao problema acreditava que, com base nas interações geradas entre cliente e produto, a partir da elaboração de uma vitrine, da alocação dos produtos no PDV e da estratégia de visual merchandising, seria possível agir diretamente sobre o comportamen- 
to de compra do consumidor. A partir dos dados obtidos, identificou-se de que forma o consumidor do segmento varejista de moda em shopping centers da cidade de Porto Alegre sofre influência das técnicas de visual merchandising e vitrinismo aplicadas pelos estabelecimentos comerciais.

Verifica-se que a elaboração correta de uma vitrine chama o cliente para o interior da loja, cria uma expectativa, comunica a identidade do estabelecimento, além de ser uma ferramenta decisiva na criação da atmosfera da mesma. Uma vitrine bem construída tem o poder de seduzir o consumidor e o induzir a comprar determinados itens. Assim como, a aplicação assertiva das técnicas de visual merchandising no interior de uma loja pode exercer intensa influência no comportamento de compra do consumidor. Aliadas à vitrine, tais técnicas são capazes de criar uma atmosfera que prende o cliente e o induz a andar pelo interior da loja em busca de novas sensações e descobertas.

Colocar produtos em pontos estratégicos induz à venda casada e à compra por impulso. Esses fatores tendem a alavancar os resultados financeiros da empresa. Viu-se, assim, que de fato, existe forte influência da vitrine e das técnicas de visual merchandising sobre o comportamento do consumidor e que sua utilização precisa ser valorizada pelo segmento varejista de moda.

\section{Conclusão e sugestões}

O visual merchandising e o vitrinismo possuem um papel mais amplo do que apenas deixar um ambiente comercial visualmente mais agradável. Detêm como função principal conquistar e reter a atenção do consumidor e induzi-lo a adquirir determinados produtos, garantindo assim, resultados financeiros positivos para a empresa. A presente monografia foi elaborada com o intuito de demonstrar o quão relevante é a correta utilização da vitrine e do visual merchandising como ferramenta de interferência sobre o comportamento do consumidor.

Essa pesquisa se deu para suprir a busca do pesquisador por embasamentos concretos sobre a relação que o vitrinismo e o visual merchandising tem com o comportamento de compra do consu- midor. Percebe-se a necessidade de demonstrar, para as empresas do segmento varejista de moda e profissionais da área de visual merchandising e vitrinismo, o quão relevante é a correta utilização das referidas técnicas como ferramenta de interferência sobre o comportamento de compra do consumidor.

Assim, o presente trabalho é caracterizado como uma pesquisa exploratória, em um estudo de recepção, que visa identificar o grau de interferência das técnicas de merchandising e vitrinismo sobre o comportamento de compra do consumidor. Usou-se da pesquisa bibliográfica para buscar conceitos e reflexões sobre o visual merchandising, o vitrinismo e sua interferência sobre o comportamento do consumidor. Através de um questionário disponibilizado em ambiente virtual e respondido por consumidores que realizam suas compras no segmento varejista de moda em shoppings centers da cidade de Porto Alegre, buscou-se identificar a relevância do uso de tais técnicas como ferramenta de interferência sobre o comportamento de compra.

Partiu-se da seguinte problemática: qual a influência do visual merchandising e do vitrinismo no comportamento de compra do consumidor, no segmento de varejo de moda, em shoppings centers de Porto Alegre? Com base na análise das respostas obtidas, conclui-se que o consumidor de fato sofre influência do vitrinismo e do visual merchandising em suas decisões de compra, sendo atraído ao interior da loja devido a correta elaboração de uma vitrine, além de ser levado a adquirir produtos específicos a partir da forma com que estão expostos no interior do estabelecimento comercial. Com esse resultado é possível inferir que as respostas obtidas contemplam a hipótese indicada no início da pesquisa, de que as técnicas de visual merchandising exercem expressiva influência sobre o comportamento de compra do consumidor.

Sendo assim, considera-se que objetivo geral deste estudo, de verificar a influência do visual merchandising e do vitrinismo no comportamento de compra do consumidor, no segmento do varejo de moda, em shopping centres da cidade de Porto Alegre foi alcançado de forma integral. Quanto aos objetivos específicos de compreen- 
der o visual merchandising no composto de marketing, descrever o uso do vitrinismo no segmento de varejo de moda, caracterizar o comportamento do consumidor que frequenta os shopping centers da cidade de Porto Alegre, com ênfase no segmento varejista de moda, estes também foram plenamente alcançados.

É relevante ressaltar a falta de autores que tratem especificamente do visual merchandising como ferramenta de interferência sobre o comportamento do consumidor, bem como a respei- to do vitrinismo. Isso se tornou um fator limitador na busca de referencial teórico sobre os assuntos.

Apesar desse aspecto, com base nos resultados obtidos através desta pesquisa, sugere-se a expansão da mesma para alcançar como as técnicas de visual merchandising e vitrinismo interferem sobre o comportamento de compra dos consumidores de áreas geográficas distintas, além de um estudo que vise identificar se tais ferramentas possuem mesmo nível de interferência em consumidores de estabelecimentos comerciais de rua. 


\section{Referências}

ABRASCE. Números do setor. Disponível em <http://www.abrasce.com.br/monitoramento/evolucao-do-setor> Acesso em 05/09/2017, as 15:00.

ASSOCIAÇÃO BRASILEIRA DA INDÚSTRIA TÊXTIL E DE CONFECÇÃO. Perfil do setor. Disponível em <http:// www.abit.org.br/cont/perfil-do-setor> Acesso em 23.04.2017, as 16:10.

BAILEY, Sarah; BAKER. Jonathan. Moda e visual merchandising. São Paulo: Editora GG, 2014.

BARDIN, Laurence. Análise de Conteúdo. 1977. Disponível em: <http://goo.gl//6HcBR>. Acesso em: 05.06.2017, ás 12:30.

BARNARD, Malcolm. Moda e Comunicação. Rio de Janeiro: Rocco, 2003.

BAUDRILLARD, Jean. A sociedade de consumo. Tradução de Artur Morão. Rio de janeiro: Elfos, 1995.

BAUMAN, Z. Modernidade Líquida. Rio de Janeiro: Jorge Zahar Ed., 2001.

Vida Para Consumo. Rio de Janeiro: Jorge Zahar Ed., 2008.

BHALLA, Swati. S, Anuraag. Visual merchandising: The only language of retail. New Delhi: Tata, 2009.

BIGAL, Solange. Vitrina: do outro lado do visível. São Paulo: Nobel, 2000.

BLESSA, Regina, Merchandising no Ponto-De-Venda. 4ª ed. São Paulo: Atlas, 2006.

CASARIN, Helen de Castro Silva; CASARIN, Samuel José. Pesquisa científica: da teoria à prática. Curitiba: Ibpex, 2011.

CHAGAS, Anivaldo Tadeu Roston. O questionário na pesquisa científica. Administração on line, v. 1, n. 1, 2000.

Disponível em < http://www.fecap.br/adm_online/art11/anival.htm> Acesso em 27.05.2017, ás 11:00.

CHURCHILL, G. A., Marketing: Criando Valor Para o Cliente. São Paulo: Saraiva, 2000.

CHURCHILL, Gilbert A.; PETER, J. Paul. Marketing: Criando valor para o cliente. São Paulo: Saraiva, 2000.

COBRA, Marcos, Administração de Marketing. São Paulo: Atlas, 1990.

Marketing e Moda. São Paulo: SENAC e Editora Cobra, 2007.

DEPARTAMENTO DE PESQUISAS E ESTUDOS ECONÔMICOS (DEPEC). Comércio varejista. Disponível em $<$ www.economiaemdia.com.br/EconomiaEmDia/pdf/infset_comercio_varejista.pdf> Acesso em 17.04.2017, às 11:00.

COSTA, Antonio R.; CRESCITELLI, Edson. Marketing promocional para mercados competitivos. São Paulo: Atlas, 2007. DEMETRESCO, Sylvia; MAIER, Huguette; Vitrinas entre Vistas. São Paulo: Editora Senac, 2004

DEMETRECO, Sylvia. Vitrina: construção de encenações. 3. ed. São Paulo: Editora SENAC São Paulo, 2007.

ENER, G. Vitimas da moda? como criamos, por que a seguimos. São Paulo: Senac, 2005.

FEIJÓ, Fabrício Rodrigues. Efeito dos fatores de design do merchandising nas vendas em varejo. 2010. Tese de Doutorado. Disponível em <http://bibliotecadigital.fgv.br/dspace/handle/10438/7816> Acesso em 21.04.2017 ás 15:11. 
FERRACIÙ, João de Simoni Soderini. Promoção de vendas. São Paulo: Makron Books, 1997.

FONSECA, J. J. S. Metodologia da pesquisa científica. Fortaleza: UEC, 2002.

FREITAS, Sebastião Nelson; NATALI, Marcos. Merchandising na Prática. São Paulo: STS, 1995.

GADE, Christiane. Psicologia do consumidor. São Paulo: EPU, 1980.

GIL, Antonio Carlos. Como elaborar projetos de pesquisa. 4. ed. São Paulo: Atlas, 2008.

Métodos e técnicas de pesquisa social. 5. ed. São Paulo: Atlas, 1999.

GOMES FILHO, João. Gestalt do objeto. Sistema de leitura Visual da Forma. São Paulo: Escrituras Editora, 2002.

GUSMÃO, Liz. Vitrinismo - saiba o que é vitrinismo - técnicas de venda. Disponível em < http://www.artigonal. $\mathrm{com} / \mathrm{marketing-e-publicidade-artigos/vitrinismo-saiba-o-que-evitrinismo-tecnicas-de-vendas-1094352.html>}$ Acesso em 16.05.2017 às 15:20.

HOGAN, Kevin. A psicologia da persuasão. Rio de Janeiro: Record, 1998.

KOTLER, Philip e ARMSTRONG, Gary, Princípios do Marketing. 15ª ed. São Paulo: Pearson Education do Brasil, 2015.

KOTLER, Philip e KELLER, Kevin Lane, Administração de Marketing. $12^{\mathrm{a}}$ ed. São Paulo: Pearson Education do Brasil, 2012.

KOTLER, Philip. Administração de Marketing: A Edição do Novo Milênio. 10ª ed. São Paulo: Prentice Hall, 2000. Administração de marketing: análise, planejamento, implementação e controle. $5^{a}$ ed. São Paulo: Atlas,

1998.

KOUMBIS, D. Varejo de moda: da gestão ao merchandising. São Paulo, Gustavo Gili, 2015.

LASNOGRODSKI, Bruno. Marketing. Porto Alegre: Ortiz, 1999.

LEVY, Michael; WEITZ, Barton A. Retailing management. 8th ed. New York: McGraw-Hill, 2012.

LIPOVETSKY, Gilles, O Império do Efêmero. São Paulo: Companhia da Letras, 2009.

MALHOTRA, Naresh. Pesquisa de Marketing: Uma orientação aplicada. Porto Alegre: Bookman, 2001.

MARCONI, Marina de Andrade; LAKATOS, Eva Maria. Fundamentos de metodologia científica. 5. ed. São Paulo: Atlas, 2003.

MARION, José Carlos. DIAS, Reinaldo; TRALDI, Maria Cristina. Monografia para os cursos de administração, contabilidade e economia. São Paulo: Atlas, 2002.

MATTAR, F. Pesquisa de marketing. São Paulo: Ed. Atlas, 1996.

MATTAR, Fauze Najib. Administração de varejo. Rio de Janeiro: Elsevier, 2011.

McCARTHY, E. Jerome; PERREAULT, William D. Jr. Marketing essencial: uma abordagem gerencial e global. São Paulo: Atlas, 1997.

MENEZES, Heloisa. Pequenos negócios no varejo de moda. Revista conhecer. 30 ed. Maio de 2015. Disponível em Disponível em <www.bibliotecas.sebrae.com.br/chronus/ARQUIVOS_CHRONUS/bds/bds.nsf/c8874f1b33de 587fcc7641cb0f839ec2/\$File/5350.pdf> Acesso em 17.04.2017, às 13:15. 
MINAYO, M. C. S. (Org.). Pesquisa social: teoria, método e criatividade. Petrópolis: Vozes, 2001.

MIRANDA, Roberto Lira. Marketing de varejo e alianças estratégicas com a indústria. Rio de Janeiro: Qualitymark, 1997.

MORAES, Roque. Análise de conteúdo. Revista Educação. 1999. Disponível em: <http://goo.gl/bPY1/Y>. Acesso em: 05.06.2017, ás 13:50.

MOTTA, Sérgio; MATTAR, Fauze Najib; OLIVEIRA, Braulio. Pesquisa de Marketing: Metodologia, Planejamento, Execução e Análise. Elsevier Brasil, 2014.

OCHOA, Carlos. Amostragem não probabilística: amostra por conveniência. Netquest, 21 out. 2015. Disponível em: <https://www.netquest.com/blog/br/blog/br/amostra-conveniencia >. Acesso em 20.05.2017, as 15:20.

O setor varejista no Brasil. Disponível em <http://www.restoque.com.br/conteudo_pt.asp?idioma=0\&conta=28\& tipo=41515> Acesso em 23.04.2017, as 15:00.

Os bairros criados por lei. Prefeitura Municipal de Porto Alegre. Disponível em <http://www2.portoalegre.rs.gov. br/spm/default.php?p_secao=129> Acesso em 05/09/2017, as 14:30.

PARENTE, Juracy; LIMEIRA, Tania M. Vidigal; BARKI, Edgard. Varejo para a baixa renda. Porto Alegre: Editora Bookman, 2008.

PARENTE, Juracy. Varejo no Brasil: gestão e estratégia. São Paulo: Atlas, 2000.

PIOVESAN, Armando, TEMPORINI, Edméa Rita. Pesquisa exploratória: procedimento metodológico para o estudo de fatores humanos no campo da saúde pública. 1995. Disponível em: <http://goo.gl/QlvQ0q>. Acesso em 31.05.2017, as 12:00.

RECH, Sandra Regina. Moda: por um fio de qualidade. Ed. da UDESC, 2002.

RICHERS, Raimer. O enigmático mais indispensável consumidor: teoria e prática. Revista da Administração, jul./ set. de 1984.

ROWLEY, J. Retailing and shopping on the internet. International Journal of Retail Distribution Management, Bradford, v. 24, n. 3, p. 26-37, 2012.

Rio Grande do Sul - Porto Alegre - Síntese das informações. Disponível em <http://cidades.ibge.gov.br/ xtras/temas.php?lang=\&codmun=431490\&idtema=16\&search=rio-grande-do-sul|porto-alegre|sintese-dasinformacoes> Acesso em 05/09/2017, as 14:00.

SACKRIDER, F.; GUIDÉ, G.; HERVÉ, D. Entre vitrinas: distribuição e visual merchandising na moda. São Paulo: Editora Senac São Paulo, 2009.

SAMARA, Beatriz Santos; MORSCH, Marco Aurélio. Comportamento do Consumidor: Conceitos e Casos. São Paulo: Pearson Prentice Hall, 2009.

SANTOS, J. O que é pós-moderno? São Paulo: Brasiliense, 2004.

SCHIFFMAN, Leon G.; KANUK, Leslie Lazar. Comportamento do consumidor. 6. ed. Rio de Janeiro: LTC, 2000.

SEBRAE. Vitrinista. Disponível em: <www.sebrae.com.br/sites/PortalSebrae/ideias/como-montar-uma-empresade-servicos-de-vitrinistas, eb297a51b9105410VgnVCM1000003b74010aRCRD> Acesso em 17.04.2017, as 16:00.

SOLOMON, Michael R. O comportamento do consumidor: comprando, possuindo e sendo. 5. ed. Porto Alegre: Bookman, 2002 
TAVARES, F. O consumo na pós-modernidade: uma perspectiva psicossociológica. Comum, 9 (22), 122-143, 2004.

TAVARES, F.; IRVING, M. Natureza S.A. - O consumo verde na lógica do Ecopoder. São Carlos, S.P: RiMaEditora, 2009.

TOLEDO, Geraldo Luciano. Marketing e Varejo: Varejo, modernização e perspectivas. São Paulo: Atlas, 1995.

ZENONE, Luiz Cláudio e BUAIRIDE, Ana Maria Ramos, Marketing da Promoção e Merchandising: Conceitos e estratégias para Ações Bem-Sucedidas. São Paulo: Pioneira Thomson Learning, 2005. 